\title{
Research evaluation and impact analysis of biological nitrogen fixation
}

\author{
M.C.S. Bantilan and C. Johansen \\ International 'Crops Research Institute for the Semi-Arid Tropics (ICRISAT), Patancheru. Andhra Pradesh 502 \\ 324. India
}

Key words: chickpea, genetics of BNF, impact analysis, nitrogen fixation, nodulation variants, Rhizobium incculation, technology adoption

Table of contents
Abstract
Introduction
Limited adoption of inoculation technology
Assessment of "need to-inoculate"
Inadequate demonstration of inoculation technology
Quality control of inoculant production
Difficulties of Rhizobium inoculation in the tropics
Economics of Rhizobium inoculation technology

The research-adoption-impact continuum

Considerations for attracting support for BNF research

Impact analysis

Benefivcost analysis

Management and genetic options

Inoculation technology

Outlook for $\mathrm{N}$ fertilizer

Conclusion

Acknowledgements

References

\section{Abstract}

Although viable Rhizobium inoculation technology for cultivated legumes has long been available, there has been little sustained adoption of this technology in tropical regions. Reasons contributing to this include inadequate demonstration of the technology, presence of adequate native rhizobia, high soil mineral nitrogen levels which suppress nitrogen fixation, inadequate quality control of Rhizobium inoculum and difficulties of inoculating under 
tropical conditions. In order to ensure a better adoption rate of existing or emerging biological nitrogen fixation (BNF) technologies, it is proposed that future research and development efforts better focus on the researchadoption-impact continuum. The salient features of this approach are described in this paper, using the example of recently developed nodulation variants in chickpea as a potential means of increasing BNF in this crop. It is suggested that previous experience with Rhizobium inoculation technology is amenable to ex-post impact analysis to analyze bottlenecks, and that ex-ante impact analysis should be built into on-going or planned BNF research, to better ensure that technology adoption occurs.

\section{Introduction}

The oil crisis of the early 1970 s, and the consequent price escalation of nitrogenous fertilizers sparked off a "BNF-boom" in research that lasted through to the early 1980s. Optimistic claims were made concerning substitution of fertilizer nitrogen $(\mathrm{N})$ by biologically fixed $\mathrm{N}$, and funds flowed to support research in biological nitrogen fixation (BNF). In the 1990s, however, there seems to be little residual effect of this BNF-boom in the fields of resource-poor farmers in developing countries, particularly in South Asia. One reason is, of course, that the oil crisis prompted the discovery of vast new oil and gas reserves, and that $\mathrm{N}$ fertilizer prices have generally stabilized at levels affordable (with or without government subsidy) to all but the poorest of farmers. Another reason is that the promising prospects concerning BNF in the 1970s have not been realized in the form of adoption of BNF technology by resource-poor farmers to any significant extent.

In India in particular, there have been several largescale schemes to introduce Rhizobium inoculation for the major legume crops (Verma and Bhattacharyya, 1992), but there is little evidence of any widespread adoption of this technology by farmers. This situation exists despite evidence from many experiments showing significant responses to inoculation (e.g. Kumar Rao, 1990) and calculations of economic viability (Verma and Bhattacharyya, 1992). This contrasts with the situation in countries such as Australia (Roughlcy and Pulsford, 1982) or Canada (Rennie and Hynes, 1993), where BNF research has led to widespread adoption of Rhizobium inoculation technology. But there the circumstances were different, with mainly introduced temperate legume species requiring specific strains of rhizobia, and with large-scale, mechanized (thus simplifying Rhizobium inoculation procedures) and commercialized farming systems. The only example of large-scale, sustained adoption of Rhizobium inoculation technology that we are aware of in Asia is the case of soybean in Thailand (Chanaseni and Kongn- goen, 1992). Here also there appears to be a need for introduction of specific rhizobia to match the introduced soybean cultivars; native rhizobia do not always adequately nodulate these cultivars.

With this history of promise offered, but little evidence of delivery in Asia (apart from Thailand), it is not unnatural that research administrators are somewhat wary of new proposals for BNF research targetted at improving the lot of small, resource-poor farmers. With respect to agriculturally-important legumes, applied research in BNF has previously been overwhelmingly directed towards Rhizobium inoculation technology, with the aim of enhancing infection and $\mathrm{N}_{2}$ fixation by addition of superior Rhizobium strains. Other options, such as manipulation of agronomic practices to favor BNF or genetically altering the plant to increase the symbiotic activity, have received less attention in the applied sense. In this paper we attempt to summarize the reasons for limited adoption of inoculation technology in Asia, suggest means of evaluating BNF research and measuring its impact at the level of farmers' fields, and give some specific suggestions for future research and development approaches.

\section{Limited adoption of inoculation technology}

Various reasons have become apparent for limited adoption by farmers of experimentally proven Rhizobium inoculation technology, in the tropics generally and in South Asia in particular.

\section{Assessment of "need-to-inoculate"}

Recommendations to inoculate are often of a universal nature (e.g. Jeswani and Baldev, 1990), to be applied across diverse environments and legume species, without apparent recognition of well established and marked site-to-site and legume species, and even cultivaral, differences in inoculation response. It is sometimes argued that, as all such differences in response cannot possibly be known or understood, inoculation may be regarded as an "insurance policy" 
with a low premium. However, before farmers, or anyone else, would be prepared to invest in "insurance" an understanding of the risks or forgone opportunities of not using the technology is needed. For effective extension of BNF technology, it appears necessary to define more carrefully than hitherto the probability of an inoculation response for a specific situation. Some major factors determining response to inoculation are as follows:

- Absence or inadequate numbers of rhizobia in the soil, native or introduced, that can effectively nodulate the target legume. Tropical legumes are largely promiscuously nodulated by Bradyrhizobium which are ubiquitous in soils where these legumes normally grow; hence the limited response of these legumes to Rhizobium inoculation (Date, 1977).

- Whether indeed the natural variation in the rhizobial germplasm has been adequately examined to identify truly superior strains for particular situations.

- Even moderate levels of soil mineral $\mathrm{N}$ inhibit nodulation (Harper and Gibson, 1984), which is not overcome by addition of more rhizobia through inoculation.

- There are large differences between and within legume species in the degree to which they can meet their own $\mathrm{N}$ needs through fixation.

- Other plant growth limiting factors strongly interact with nitrogen fixation.

- The quality of the Rhizobium inoculum and the effectiveness of the inoculation technique.

The INLIT (International Network of Legume Inoculation Trials) approach (Davis et al., 1985) of NifTAL (Nitrogen Fixation by Tropical Agricultural Legumes), University of Hawaii, remains a valid approach to determine the need-to-inoculate. Treatments consist of an uninoculated control, an inoculated treatment, a treatment with "optimum" $\mathrm{N}$ fertilizer, and presence or absence of another major limiting factor for the legume (usually phosphorus). As multilocational field trials are expensive, various preliminary tests can give an indication as to likely response. An example is the use of simple models relating inoculation responsiveness to most probable number (MPN) of effective rhizobia and level of soil mineral N (Singleton et al., 1992).

\section{Inadequate demonstration of inoculation technology}

Activities in BNF technology have often remained within the discipline of "soil microbiology" with inade- quate interaction with other disciplines, let alone extension personnel. There is little evidence that the demonstration and extension process for BNF technology. (1) accompany other improved practices, has heen thoroughly thought through and effectively applied on a farm-scale basis.

\section{Quality control of inoculamt production}

In the tropics, there are few cases where Rhizobium inoculant production systems of consistently adequate quality have heen estahlished and maintained over a reasonable period. Shortcomings and their suggested remedies have been described by Thompson (1984. 1991).

\section{Difficulties of Rhizohium inoculation in the tropics}

High temperatures typical of tropical and sub-tropical environments mitigate against continued viability of Rhizobium in earrier packets, even if their numbers had been adequate initially (Somasegaran et al., 1984). Normal sowing times of legumes in these regions, at the beginning and end (for crops to be grown on residual soil moisture) of a summer rainy season, are normally hot periods (ambient maximum temperatures $>30^{\circ} \mathrm{C}$ ) where exposure of cultures to lethal temperatures during the storage and inoculation processes is almost unavoidable, even with refrigeration available. Further, if the inoculum is prepared as non-sterile, higher temperatures may favor competitors of Rhizobium. More work is needed to develop robust procedures that would minimize adverse high temperature effects.

\section{Economics of Rhizobium inoculation technology}

Although calculations of the economic viability of introducing inoculation technology have been done and high trates of return asserted (e.g. Verma and Bhattacharyya, 1992), these calculations often have deficiencies. For example, production costs are often subsidized by government agencies and personnel costs are sometimes ignored; actual costs are therefore underestimated. There can be mis-calculation of expected returns, based on inoculation responses extrapolated over regions, and costs in terms of time or skill required for effective inoculation at the normally busy time of sowing are often overlooked. A more thorough, and more conservative, accounting is desirable to convincingly present likely returns on investment in Rhizobium inoculation technology. 
Level of adoption (\%) 100

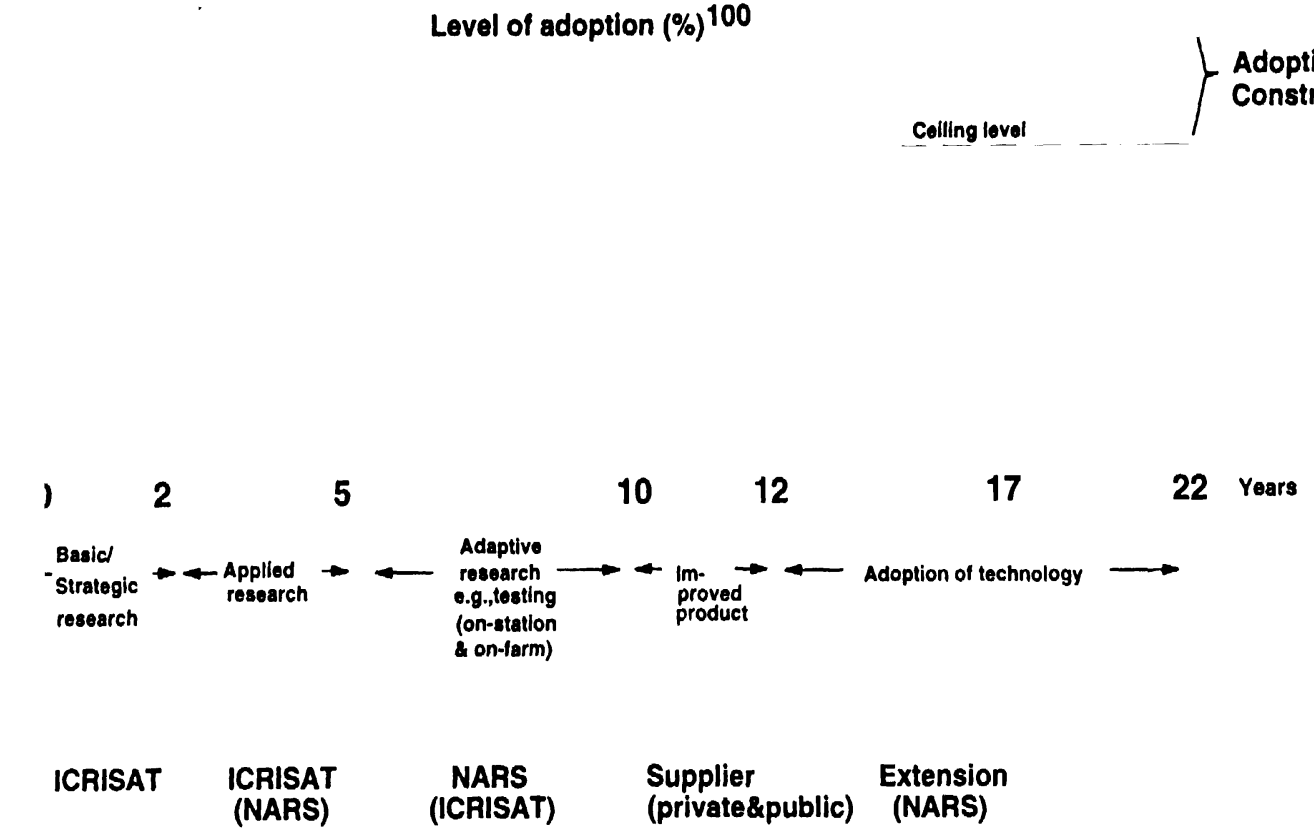

Fig. l. Schematic representation of the research, development and adoption process over time, indicating relative involvement of ICRISAT and national agricultural research systems (NARS).

\section{The research-adoption-impact continuum}

It is suggested that future proposals for BNF research, that claim to be ultimately directed towards farmers' fields, be considered in the light of the entire continuum from basic research to impact assessment. Particularly with an increasing scarcity of resources, more and more the bottom line of any research undertaking is its impact or likely impact. To facilitate the conduct of impact assessment, both ex-post (after the event) and ex-ante (before the event), an understanding of the whole research process is essential.

The research-evaluation continuum may be systematically viewed by using a general framework (Davis et al., 1994) which traces the development of the different components of the research process, its output and logical conscyuences. The conceptualization of the framework starts with the consideration of research investments which are used to fund a specific research project, designed to develop a new technology for use by farmers. If the research project does successfully achieve its objectives, it usually generates research output in the form of, first, some new knowledge and then a change in the technology for use by farmers. To be more specific, the application of science-based technologies resulting from BNF research is expected to bring about increases in yield and product quality from crops presently planted or from those which are subsequently planted. BNF research is also expected to improve the efficiency of input use via agronomic practices and crop management. Ultimately, the above changes in the production and consumption environment are iranslated into upgrading of the welfare of farmers who use the technology as well as of consumers who use the final products. Further, the environmental benefits of greater reliance on BNF in cropping systems are elaborated below and elsewhere in this volume.

Before the final benefits of rescarch accrue to society (i.e. producers and consumers), two important conditions must be met. First, the rescarch undertaken must be successful in achieving its targeted objectives. This introduces the notion of probability of success or relative research capability, relating to the risk involved in most research which could mean that an intended technological improvement may not indeed eventuate, even after a significant period of experimentation or investigation. Second, the potential increase in production promised by a new technology is ultimately achieved only when the technology is adopted and utilized by farmers. If the technology does not result in an improvement in some way over existing technolo- 
gies then farmers are unlikely to use it. In this case the technology, although developed, is redundant. Even if it does unambigously result in improved conditions some farmers may still not adopt it. Several reasons may explain this, one of which is that there may be reluctance among'farmers to deviate from well-tried, and in their opinion proven, practices. This condition necessitates the consideration of rates of technology adoption and the factors constraining it.

The measurement of the welfare gain to society is incomplete if it does not take into account the externalities which the technology involves. The externality consideration in this framework may either be negative or positive. Classic examples of negative externalities are human-induced soil erosion in agriculture and detrimental effects of chemical-based technology. The long list of effects of the latter example includes the deleterious effect of pesticides on the health of farmers and their families, the transmittal of chemical residues through the food chain to consumers. the toxic effect of chemicals on animals like fish, shrimps, frogs and helpful insects in the farmers' fields, the contamination of ground and surface waters, and the reduction of microorganism populations in the soil that help sustain soil fertility.

The positive externalities are incorporated within the above framework through consideration of the concept of spillover effects. Three types of spillover effects are possible (Bantilan and Davis, 1991). The first type involves across-location spillovers wherein a technology developed through research for one product in a specific location can be adapted to improve the production efficiency' of the same product in other locations (geo-political or agro-ecological). The consideration of this type of spillover effect is relevant because the applicability of the new technology may not be the same for all locations as these locations refer to production environments differentiated by agronomic, climatological and ecological factors.

The second type of spillover effect refers to acrosscommodity applicability of the technology developed. For example, a cultural management technique developed specifically for groundnut production may also potentially improve the efficiency of production of other legumes.

The nature of the first two types of spillover effects reflects the direct applicability of a technology across different locations/production environments and across different commodities. Thus, they are referred to as direct spillover effects.
A third type of spillover effect is referred 10 as the indirect or price spillover effects. Because lechnological change for a particular commodity in a specific location brings forth increased supply which may cause price changes, then the price effect on other locations (if the commodities are traded) or its price effect on related commodities may have significance. This is particularly relevant when the elasticities of the product demand are relatively small and/or the rate of product transformation among commodities is significant.

Another factor which can influence welfare gains due to research is existing government policies. These policies influence the production and/or consumption of a commodity, or inputs used to produce it. They can influence both the benefits flowing from research and the distribution of these benetits.

The welfare effects which can flow from a research effort can vary significantly among research efforts, regions, and commodities. Choices among research options are likely to be influenced by the magnitude and distribution of these effects. Which ones are important requires clarification. For example, if two regions are part of one country and if the total national welfare gain is the objective of the research institutions, then a measure of the research impact of this objective is provided by adding all the gains (or losses) of all sectors. If, however, the objective is to maximize gains to poor farmers only. the subse of welfare changes to this particular sector is added to give a measure of how well the research option may satisfy this ohjective. Estimates of these welfare changes, if quantified, can be summarized in a form suitable to assist decision-makers in setting research priorities or other allocation decisions. This information is combined with other information before decision-makers make final judgments about allocation decisions.

Other aspects for consideration are: a) effect on income distribution and poverty; h) food security; c) human capital development; $d$ ) institution building and strengthening of national programs; e) employment generation; f) sustainability and environmental impact; and $g$ ) implications on policy change.

It is clear that a spectrum of considerations has to be taken into account with regard to the assessment of a research project, both ex-posi with respect to impact achieved by a completed project and ex-ante with respect to impact likely to be achieved by a proposed project. It is equally clear that a detailed understanding of the components of the research-evaluation continuum is necessary in arriving at a quantitative 
assessment of impact. What follows is a sketch of the type of information needed, both ex-post and exante, in the assessment of an example of BNF research that is directed towards proving $\mathrm{N}_{2}$ fixation ability of chickpea (Rupela and Johansen, 1992). Improving $\mathrm{N}_{2}$ fixation potential of chickpea cultivars involves the following activities:

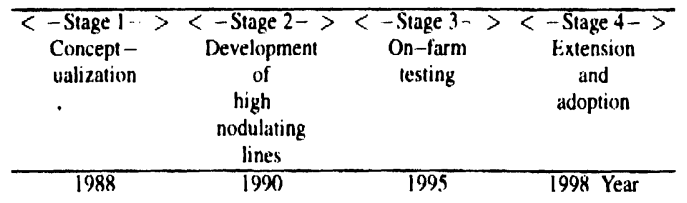

Stage 1 involved the development of the concept of genetic alteration of the plant for hetter nodulation, through selections within existing cultivars (Rupela and Johansen, 1992). This stage led to the basic concepts and methodology for the development of the improved technology. Stage 2 involves actual conduct of the prescribed selection procedure to identify lines with superior $\mathrm{N}_{2}$ fixation capability and thcir validation in on-station experiments. Stage 3 involves onfarm validation of the value of the selections. Stages 1, 2 and 3 represent the basic, applied and adaptive research components in the development of this technology.

Stage 4 is the demonstration, extension and adoption of the technology among farmers. The process underlying the adoption of technologies (Bantilan, 1993) is represented by the curve in Figure 1, in which adoption-related variables are highlighted: adoption lags, rate of adoption and ceiling level of adoption. Introduction of a new technology is not usually met with immediate adoption. The gestation period between the generation of a technology and its adoption varies by sector, commodity and type of technology. There are farmers who adopt only after the effects have been convincingly demonstrated. Reluctance among farmers to adopt a technology may be due to difficulty in its use, unavailability of the inputs required, market uncertainty, price fluctuations or preference for very low management crop technology. Thus, a sigmoid adoption curve is usually used to illustrate the adoption process; where the level of adoption is initially low, rises at an increasing rate after sufficient diffusion is attained, and finally reaches a ceiling level of adoption.

The quantitative assessment of impact requires some basic data. Data on the key factors involved in the various stages of the research process (Fig. 1) are needed to estimate the expected impact of BNF research.
An important feature of the BNF research example described above is that the expected research/adoption lag is about 10 years. This represents the time it takes until the envisioned technology is achieved, validated and made available to farmers. The probability of achieving the expected research results (probability of success) has to be estimated, particularly for stages 1 , 2 and 3. Estimates on the rate of technology adoption and ceiling level of adoption, which may vary considerably among types of farmers, have to be obtained. The cost of the actual implementation of the research in the first three stages should be taken into account in the overall assessment of benefit/cost ratios for the research endeavor.

\section{Considerations for attracting support for BNF research}

\section{Impact analysis}

It is suggested that proposals for BNF research and development would be much more attractive to research administrators and donors if it could be clearly shown how proposed activities fit into the entire research-adoption-impact continuum. They need to be based on sound calculations of expected gains from research and other parameters of the adoption curve. Considering previous limited adoption of BNF technology there is scope for adoption constraint studies, to pinpoint bottlenecks. Impact analysis should be built into any proposed project. Improvement of BNF would seem a readily quantifiable candidate for this suggested systematic and holistic approach, as ammenable data sets are likely to be available.

\section{Benefit/cost analysis}

An important first step in ex-ante impact analysis, as a basis for a project proposal, is a rigorous benefit/cost projection. A prime requirement is to establish, for particular target legumes and cropping systems, the actual gains to be expected from improving BNF above an existing level, in comparison to achieving these gains by using mineral $\mathrm{N}$ fertilizer. This firstly requires assessment of the extent to which the legume can nieet its $\mathbf{N}$ needs through fixation. Essentially, needto-inoculate studies (see above) supplemented by more detailed studies on rates and time of application of $\mathrm{N}$ fertilizer, can accomplish this (although there would inevitably be some difficulties of interpretation related 
to fertilizer $\mathrm{N}$-use efficiency and $\mathrm{N}$ metabolism within the plant). Further, the residual value of legumes. in terms of equivalents of $\mathrm{N}$ fertilizer applied to a subsequent crop, needs to calculated. Also, relative value of $\mathbf{N}$ derived from either fertilizer or organic matter sources needs to be estimated, from the viewpoint of environment protection and sustainability of cropping systems. These data provide a baseline against which to estimate gains that can be expected from further improving BNF as a result of research or by direct application of known technologies. With discounting for factors such as probability of success, time lags and ceiling rate of adoption, reasonable estimates can be made for costs and benefits of a suggested research and/or development effort (Davis et al., 1987, 1994; Edwards and Freebairn, 1984; Norton and Davis, 1981: McKenney et al., 1991).

\section{Management and genetic options}

A careful evaluation is needed of management (primarily inoculation technology) and genetic options for enhancing BNF, in view of the new genetic options being proposed (e.g. Rupela and Johansen, 1992, 1994). If we can genetically alter the plant to better accept native rhizobia in an effective symbiosis, especially within existing cultivars, that would both meet the legumes' $N$ needs as well as leave substantial residual $\mathrm{N}$, then the aforementioned problems of inoculation technology can to some extent be bypassed. But, this assessment does depend on knowledge of to what extent the target legumes are currently limited by $\mathrm{N}$, as explained in the previous section.

\section{Inoculation technology}

If it is decided that further pursuit of Rhizobium inoculation technology is viable then the shortcomings discussed earlier need to be comprehensively addressed.

\section{Outlook for $N$ fertilizer}

The popularity of BNF research, and hence the degree of funding for it, is directly and closely related to the relative (compared with other agricultural inputs) price of $\mathrm{N}$ fertilizer. More emphasis should be given to comprehensive comparisons of BNF enhancement versus use of $\mathrm{N}$ fertilizer. This not only involves relative input costs, in relation to benefits expected, but also adverse consequences of use of either $\mathrm{N}$ source. For example, reliance on $\mathrm{N}$ fertilizer can result in soil acidification,
$\mathrm{N}$ leaching losses and eutrophication of water bodies. But reliance on BNF can also lead to soil aciditication (e.g. by proton excretion from legume roots (Marschner. 1986)) and inflexibility of cropping systems (particularly if legumes are a low value cropping option).

\section{Conclusion}

The need for shifting the balance from fertilizer derived $\mathrm{N}$ to $\mathrm{N}$ derived from $\mathrm{BNF}$ to meet the $\mathrm{N}$ nutritional needs of crop plants is as imperative as it ever was. In addition to well established management options for doing this, such as Rhizobium inoculation technology, there are increasingly feasible options hecoming available for genetic enhancement of the host legumes' ability to fix N. However, the relatively poor adoption record of long-established BNF technologies. and inoculation technology in particular, suggest that caution is needed in preparing project proposals for research aimed at enhancing BNF. We thus advocate use of ex-ante impact analyses for development of such proposals, with careful estimation of henefivcost ratios. Further, impact analysis should be written into future research proposals such that movement along the research-adoption-impact continuum can be monitored, any necessary mid-course adjustments made. and ex-post impact assessments done.

\section{Acknowledgements}

We thank Drs D McDonald, O P Rupela and J V D K Kumar Rao, ICRISAT, Dr P W Singleton, NifTAL, and Dr J K Ladha, IRRI, for helpful comments on the manuscript.

\section{References}

Bantilan M C S 1993 Technology adoption and economic assessment of on-farm adaptive research. In Approaches to On-farm Research in Asia: Summary Proceedings of the Regional Workshop on OnFarm Adaptive Research, 18-20 February 1993, Ho Chi Minh City, Vietnam. pp 21-27. ICRISAT, Patancheru, India.

Bantilan M C S and Davis J S 1991 Across-commodity spillover effects of research and opportunity costs in a multi-product production environment. ACIAR/ISNAR Project Paper No. 30. Australian Center for International Agricultural Research, Canberra, Australia/International Service for National Agricultural Research, The Hague, Netherlands. 24p. 
Chanaseni C and Kongngoen S 1992 Extension programs to promote rhizobial inoculants for soybean and groundnut in Thailand. Can. J. Microbiol. 38. 594-597.

Date R A 1977 Inoculation of tropical pasture legumes. In Exploiting the Legume-Rhizobium Symbiosis in Tropical Agriculture. Proceedings of a Workshop. August, 1976. University of Hawaii. College of Tropical Agriculture, Miscellaneous Publication No. 145. pp 293-311. University of Hawaii. Honolulu. USA.

Davis J S. Bantilan M C S and Ryan J G 1994 Development of information systems'to suppon research decision making: An overall perspective. In Designing Information Systems to Support Priority Assessments in Agricultural Research: Concepts and Practices for International and National Institutions. Eds. J S Davis and J G Ryan. Monograph No. 17. Australian Center for International Agricultural Research (ACIAR), Canberra, Australia. (In press).

Davis J S. Oram P A and Ryan J G 1987 Assessment of Agricultural Research Priorities: An International Perspective. Australian Center for International Agricultural Research. Monograph No. 7. Canberra, Australia.

Davis R J, Cady F B, Wood C L and Chan C P Y 1985 Design and analysis of an international experimental network: legurne inoculation trials in the NifTAL Project, the INLIT experience. Research Series 042, College of Tropical Agriculture and Human Resources, University of Hawaii. University of Hawaii, HonoluIu. USA. 43p.

Edwards G W and Freebairn J W 1984 The gains from research into tradeable commodities. Am. J. Agric. Econ. 66 (324), $41-49$

Harper J E and Gibson A H 1984 Differential nodulation tolerance to nitrate among legume species. Crop Sci. 24, 797-801.

Jeswani L M and Baldev B 1990 Advances in Pulses Production Technology. Indian Council of Agricultural Research, New Delhi. India. 190p.

Kumar Rao J V D K 1990 Pigeonpea: nitrogen fixation. In The Pigeonpea. Eds. Y L Nene, S D Hall and V K Sheila. pp 233-256. CAB Int., Wallingford, UK.

Marschner H 1986 Mineral Nutrition in Higher Plants. Academic Press, Harcourt Brace Jovanovich, Publishers, London. 674p

McKenney D W. Davis J S. Turnbull J W and Searle S D 1991 The impact of Australian Tree Species Research in China. ACIAR Economic Assessment Series No. 12. Australian Centre for International Agricultural Research, Canberra. 18p.
Norton G W and Davis J S 1981 Evaluating returns to agnicultural research: a review. Am. J. Agnc. Econ 6.3. 685-99

Rennic $R J$ and Hytes $R K 109.3$ Scientitic and legislature control of legume inoculants for lentil and field pea J Prod Agric o(t). $569-74$.

Roughley R J and Pulsford D J 1982 Production and control of legume incculants In Nitrogen Fixation in Legunkes. Ed. J M Vincent. pp 143-2(19. Aciademic Press. Sydney. Australta

Rupela () P and Johansen C 1992 Genetic variation for nodulation within chickpea cultivars. Paper presented in the Resciarch Corordination Meeting of IAEA "The Lise of lsotopes's in Increasing the Yield and Nitrogen Fixation Capabilites of Common Grain Legumes in Asia", 13-17 July 1992. Hartin. China.

Rupela O P and Johansen ( 1994 Prospects for developing high mineral $\mathrm{N}_{\text {tolerant }} \mathrm{N}_{2}$-fixation in legumes - A proposal. In Proceedings of the Intemational Conference of Commısson IV. International Society of Soil Science. 1...3 1)ec 1942. Dhakad. Bangladesh (In press).

Singleton P. Thies J and Bohl(x)l B B 1992 Useful models lo predict response to legume incculation. In Biological Nitrogen Fixation and Sustainability of Tropical Agriculture. Eds. K Mulongoy. $M$ Gueye and DS C Spencer pp 245-256 John Wilcy and Soms. Chichester. UK

Somasegaran P. Reyes V G and Hoten H J 1984 The influence of high temperatures on the growth and survival of R/n:obmum spp in peat inoculants during preparation, storage and distribution Can. J. Microhiol. 30. 23 30.

Thompson J A 1984 Production and quallty control of carricrhased legume inoculants. Information Bulletin No. 17. ICRISAT, Patancheru. India. 37p

Thompson J A 1991 Legume inoculant production and quality control. In Expert Consultation on Legume Incxialant Production and Quality Control, Rome, 19-21 March, 1991. pp 15-32. FAO. Rome.

Verma $L N$ and Bhattacharyya $P 1992$ Production. distribution and promotion of biofertilisers. In Fertilisers, (Jrgantc Manures. Recyclable Wastes and Biofertilisers. Ed. H L.S Tandon. pp 1.32147. Fertilizer Development and Consultation Organization. New Delhi. 